\title{
A New Technique in Ranking of Alternatives; Keen Analysis Surge of Advantage States
}

\author{
A. M. El-Kassas \\ Department of Production Engineering and Mechanical Design, \\ Faculty of Engineering, Tanta University, Tanta, Egypt \\ ahmed.elkassas@f-eng.tanta.edu.eg
}

\begin{abstract}
This paper presents a new dimensionless technique for decision-making. The new technique is the keen Analysis Surge of Advantage States of Alternatives with respect to its criterion for appreciates the incontestable value. This technique depends on the real advantage of all alternatives with the new definitions of concordance and discordance indices especially that have not the same unit. The advantages can be summarized as follows; don't cause a redundant evaluation and also provide a clear ranking of alternatives with priority vector, capability in introducing the actual comparisons between alternative, clarify the effective relations between alternatives, gives a priority vector with actual outranking relations and robust ranking of alternatives. Numerical example introduced with actual estimation.
\end{abstract}

Keyword - Concordance, Discordance, Ranking of alternatives, Outranking

\section{INTRODUCTION}

MCDM techniques which based on pairwise comparisons and physical or monetary values of alternatives are non-compensatory techniques. It starts by comparing each action to each of the others, in relation to each criterion [1]-[3], [5], [6]. The comparisons is based on calculating the concordance measure which represents the degree of dominance of alternative Ak over alternative Al for all criterion and discordance measure is carried out in concordance analysis for each pair of alternatives. It aggregates the results of all comparisons and builds the model for outranking relations according to the notion of concordance and discordance. These methods may be uses this results in the second phase of fuzzy relation exploitation, to construct two complete preorders through a descending and an a sending distillation procedure [7]. A partial preorder is elaborated as the intersection of the two complete preorders. The comparative analysis of preorders leads to a final robust result or a model re-analysis. Most of researchers have directed the intention to choosing a realistic values of indifference, preference and veto thresholds, Rogers and Bruen [8], weighting the criteria [9].

\section{CRITICISM OF MCDM}

MCDM techniques which depends on physical or monetary values of alternatives have some contradictions in most steps of analysis. The first contradiction was appeared on the condition of overlapping of any alternative to other with respect to each criterion in concordance index. If $g_{j}\left(A_{k}\right)$ is more than or equal $g_{j}\left(A_{l}\right)$, this means that $A_{k}$ is at least as good as $A_{l}$ with respect to $j^{\text {th }}$ criterion andalso, the concordance value becomes one. This sequence of estimations causes of a weakness and redundancy in concordance index, where activate the equality of alternatives in the direction of concordance, and also don't differentiate between the degree of advantages between alternatives as long as it validates the condition of concordance. The concordance values are interpreted simple as the percentage of criteria where one alternative is at least as good as the other without clear evidence to neglect the contribution of each criteria with respect to others. The second contradiction was observed in discordance index which expresses the degree that an alternative $A_{k}$ is worse than a competing alternative $A_{l}$. The concordance index is the maximum element of the set that contains the ratios of the amount of discordance between $A_{k}$ and $A_{l}$ for each criterion indicating discordance, to the maximum discordance between any pair of actions for the corresponding criterion. In ELECTRE III, calculation of discordance depends on a further threshold called a veto threshold, where concordance depends on another threshold and unlike concordance, no aggregation over criteria takes places; one discordant criterion is sufficient to discard outranking. The units of discordance do not compatible with the units of concordance, furthermore, unfairness in the choice of max discordance in the set of discordance. Therefore, this paper presents a new technique able to correct the weakness in concept of concordance and discordance estimations and its units, moreover the improvements of flaw in ELECTRE methods. The new technique is the Keen Analysis Surge of Advantage States (KASAS) of alternatives with respect to its criterion. This technique depends on the real advantage of all alternatives with the new constraints of concordance and discordance indices. keen Analysis Surge of Advantage States able to introduce the actual comparisons between alternative, clarify the effective relations between alternatives, gives a priority vector with actual outranking relations and robust ranking of alternatives. Numerical example is introduced with actual estimations. 


\section{A. Performance Matrix}

\section{MATERIALS AND MethodS}

Most of the MCDM methods require that assign the weights of importance for each attribute. Usually, these weights normalized to add up to one. Therefore, MCDM problems has expressed in matrix format. a decision matrix (performance matrix) $A$ is an $(M * N)$ matrix in which elements $a_{i j}$ indicate the performance of alternative $A_{i}$ with respect to $j^{\text {th }}$ criteria [10].

The performance of alternatives is evaluated in terms of decision criterion $C_{j}$ (for $i=1,2,3, \ldots, M$ and $j=1,2,3, \ldots, N)$. It is also assumed that the decision maker has determined the weights of relative performance of the decision criteria (denoted as $W_{j}$, for $j=1,2,3, \ldots, N$ ). This information is best summarized in the performance matrix as indicated in Figure 1.

$$
\begin{array}{cccccc}
\multicolumn{8}{c}{\text { Criteria }} \\
& C_{1} & C_{2} & C_{3} & \ldots & C_{N} \\
\text { Alt } & W_{1} & W_{2} & W_{3} & \ldots & W_{N} \\
A_{1} & a_{11} & a_{12} & a_{13} & \ldots & a_{1 N} \\
A_{2} & a_{21} & a_{22} & a_{23} & \ldots & a_{2 N} \\
A_{3} & a_{31} & a_{32} & a_{33} & \ldots & a_{3 N} \\
\vdots & \vdots & \vdots & \vdots & \ddots & \vdots \\
A_{M} & a_{M 1} & a_{M 2} & a_{M 3} & \cdots & a_{M N}
\end{array}
$$

Figure 1: A Typical performance matrix

After construction of performance matrix of alternatives with respect to its criterion the used technique has been applied.

\section{B. Keen Analysis Surge of Advantage States (KASAS)}

The major difference of any MCDM technique is the pholosoghy in performance of alternatives with respect to its criterion. Therefore, this technique depends on the outcoming steps.

1) Detrmination of concordance set

The concordance set $C_{k l}$ of two alternatives $A_{k}$ and $A_{l}$, where $k \in M$ and $l \geq 1$, is defined as the set of all criteria for which $A_{k}$ is preferred to $A_{l}$ as indicated in equation 1:

$$
\begin{array}{ll}
C_{k l}=\{j\} \text { such that } a_{k j}>a_{l j} & \text { for } j=1,2,3, \ldots, N \\
& \text { and } k \neq l
\end{array}
$$

From equation 1 it is shown that when the comparison occures between $A_{k}$ and $A_{l}$, then the alternative $A_{k}$ is preffered than $A_{l}$ at criterionjonly if $a_{k j}>a_{l j}$. Therefore, if comparison occures between $A_{l}$ and $A_{k}$, then the alternative $A_{l}$ is not preffered than $A_{k}$ at criterion $j$.

Equation 1 neglicts the equality between any two alternatives with respect to each criterion to delete aredundnt of weights on each comparison and permits the correct prefrence relations between any two alternatives due to controversial without advantages.

\section{2) Discordance Sets}

The complementary subset of concordance is called the discordance set and it is described as in equation 2 :

$$
\begin{array}{r}
D_{k l}=\{j\} \text { such that } a_{k j}<a_{l j} \quad \text { for } j=1,2,3, \ldots, N \\
\text { and } k \neq l
\end{array}
$$

From equations 1 and 2, it is shown that two complementary sets must be estimated without any intersections that resulted from the equality and the decision will be depends on the computation between two sets.

\section{3) Construction of concordancematrix}

The new technique suggested that the degree of difference between alternatives under each criterion must be known. This degree is the contribution in concordance between any two alternatives. So, the degree of difference between any two alternatives $A_{k}$ and $A_{l}$ under criterion $j$ is denoted by $D . D_{j} . A_{k} / A_{l}$ and defined by equation 3 as follows:

$$
\begin{array}{r}
\text { D. } D_{j} . A_{k} / A_{l}=a_{k j}-a_{l j} \quad \text { for } j=1,2,3, \ldots, N \\
\text { and } k \neq l
\end{array}
$$


The positive difference between any two alternatives belongs to concordance set and this degree of difference is the contribution in concordance of these alternatives under its criterion. Therefore, the max difference under each criterion $\left(\left|M . D_{j}\right|\right)$ between any two alternatives should be estimated. The contribution of relation between any two alternatives $A_{k}$ and $A_{l}$ under any jeriterion in concordance index is defined in equation 4.

The outranking relation of concordance of $A_{k} / A_{l} i s\left(C_{j} A_{k} / A_{l}\right)=\frac{D \cdot D_{j} \cdot A_{k} / A_{l}}{\left|M . D_{j}\right|}$ and so,

$$
C_{j} A_{k} / A_{l}=\frac{a_{k j}-a_{l j}}{\left|M . D_{j}\right|} \quad \begin{array}{r}
\text { for } k=1,2,3, \ldots, M \\
k \neq l \text { and } C_{j} A_{k} / A_{l}>0
\end{array}
$$

This contribution is the partial outranking between $A_{k}$ and $A_{l}$ in concordance index. Thus, the concordance value $C_{k l}$ that indicates the relative importance of alternative $A_{k}$ over $A_{l}$ with respect to all criterion is the sum of multiplication of contributions with its criterion weights as defined in equation 5 as follows:

$$
C_{k l}=\sum_{j=1}^{j=N} W_{j}\left(C_{j} A_{k} / A_{l}\right)
$$

$$
\begin{aligned}
& \text { for } k ; l=1,2,3, \ldots, M \\
& k \neq l \text { and } C_{j} A_{k} / A_{l}>0
\end{aligned}
$$

Therefore, the concordance matrix $C$ is constructed from concordance values $C_{k l}\left(0<C_{k l}<1\right)$ and is defined as follows:

$$
C=\left[\begin{array}{ccccc}
0 & C_{12} & C_{13} & \cdots & C_{1 M} \\
C_{21} & 0 & C_{23} & \cdots & C_{2 M} \\
C_{31} & C_{32} & 0 & \cdots & C_{3 M} \\
\vdots & \vdots & \vdots & \ddots & \vdots \\
C_{M 1} & C_{M 2} & C_{M 3} & \cdots & 0
\end{array}\right]
$$

It should be noted that here the entries of matrix are equal zero due to the equality.

\section{4) Construction of discordance matrix}

The discordance matrix $D$ expresses the degree that a certain alternative $A_{k}$ is worse than a competing alternative $A_{l}$ relative to each criterion. From the discordance set $D_{k l}$ in equation 2 , it is shown that the complementary subset of concordance is the set that has the negative difference between alternatives as indicated in equation 3. The same philosophy of the degree of difference in concordance is also applied in discordance with the negative difference. Thus, the contribution of relation between the alternatives $A_{k}$ and $A_{l}$ in discordance index under each criterion is defined in equation 6 as follows:

$$
d_{j} A_{k} / A_{l}=\frac{a_{k j}-a_{l j}}{\left|M . D_{j}\right|} \quad \begin{array}{r}
\text { for } k ; l=1,2,3, \ldots, M \\
k \neq l \text { and } d_{j} A_{k} / A_{l}>0
\end{array}
$$

The discordance value $d_{k l}$ that indicates the poorness of alternative $A_{k}$ with respect to $A_{l}$ as shown in equation 7 is the sum of multiplication of contribution under criterion $j$ with criterion weight for all criterion and in indicated as follows:

$$
d_{k l}=\sum_{j=1}^{N} W_{j}\left(d_{j} A_{k} / A_{l}\right) \quad \begin{array}{r}
\text { for } k ; l=1,2,3, \ldots, M \\
k \neq l \text { and } d_{j} A_{k} / A_{l}>0
\end{array}
$$

So, discordance matrix $D$ is constructed from discordance values $d_{k l}\left(-1<d_{k l}<0\right)$ and is constructed as follows:

$$
D=\left[\begin{array}{ccccc}
0 & d_{12} & d_{13} & \cdots & d_{1 M} \\
d_{21} & 0 & d_{23} & \cdots & d_{2 M} \\
d_{31} & d_{32} & 0 & \cdots & d_{3 M} \\
\vdots & \vdots & \vdots & \ddots & \vdots \\
d_{M 1} & d_{M 2} & d_{M 3} & \cdots & 0
\end{array}\right]
$$

It should be noted that here the entries of matrix are equal zero due to the equality. 


\section{5) Preference of alternatives}

From the concordance matrix, the outranking of any alternative to others was identified. Where, row one indicates the outranking of alternative number one to all other alternatives with the effects of criterion weights. Thus, sum of rows is the score of dominance of row alternative to all others. So, the Preference of dominance of any alternative $A_{k}$ is constructed as follows:

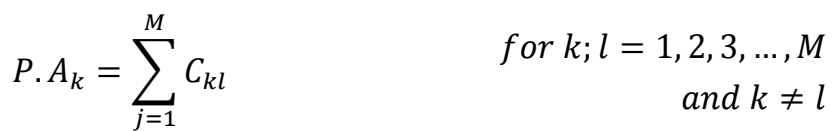

The priority values of dominance are the priority vector of dominance which has one column and $M$ rows as indicated as in equation (9). The maximum value in priority vector of dominance candidates the alternative to be an optimal alternative depends on the required order.

$$
P=\left[P . A_{1}, P . A_{2}, P . A_{3}, \ldots, P . A_{M-1}, P . A_{M}\right]^{T}
$$

In the discordance matrix, each row indicates the degree of outranked of $A_{k}$ by other alternatives. Therefore, the sum of each row is the score of outranked of each alternative by others. Thus, the discordance of any alternative $A_{k}$ is constructed as follows:

$$
\begin{array}{r}
\text { D. } A_{k}=\sum_{j=1}^{M} d_{k l} \quad \text { for } k ; l=1,2,3, \ldots, M \\
\text { and } k \neq l
\end{array}
$$

The Total discordance (T.D) is the priority vector of discordance which has one column and $M$ rows. The minimum value of discordance candidates the alternative to be optimal where all members are negative.

\section{6) Ranking of alternatives}

$$
\text { T. } D=\left[D . A_{1}, D . A_{2}, D . A_{3}, \ldots, D . A_{M-1}, D . A_{M}\right]^{T}
$$

The Ranking of alternatives generally depends on the required decision. If the required decision is the optimal alternative that ouranke all other alternatives, the alternative that has high score in priority vector of dominance is the optimal alternative (profit). If the the required decision is the optimal alternative that has less outranked from other alternatives (cost), the alternative that has the minimum value (negative value) in the priority vector of discordance is the optimal alternative.

Globally, the optimal ranking is estimated by summation of the corresponding values in the priority vector of dominance and in the priority vector of discordance and is represented in ranking vector $(R . V)$ as follows:

$$
R . V=\left[P . A_{1}, P . A_{2}, P . A_{3}, \ldots, P . A_{M-1}, P . A_{M}\right]^{T}+\left[D . A_{1}, D . A_{2}, D . A_{3}, \ldots, D . A_{M-1}, D . A_{M}\right]^{T}
$$

Therefore, the alternative that has high score is the optimal alternative than others and vice versa. Ranking of alternative is constructed depends on the priority vector values. Ranking of alternatives indicates the outranking of any alternative to athers, so, the outranking relation will be discussed in the next division.

\section{7) Outranking relations}

The outranking relations is constructed by means of a threshold value in the concordance index. For example, $A_{k}$ will only have a chance to dominate $A_{l}$ if its corresponding concordance index $C_{k l}$ exceeds at least a certain threshold value $\underline{C}$. That is, the following is true: $C_{k l}>\underline{C}$. The threshold value $\underline{C}$ can be determined as the average concordance index. That is, the following relation is true:

$$
\underline{C}=\frac{1}{M(M+1)} \sum_{k=1}^{M} \sum_{l=1}^{M} C_{k l} ; \text { where } l \neq k
$$

The threshold value $\underline{d}$ can be determined as the average discordance index, where $\underline{d i s}$ defined as follows:

$$
\underline{d}=\frac{1}{M(M+1)} \sum_{k=1}^{M} \sum_{l=1}^{M} d_{k l} \quad \text { where } l \neq k
$$

Once the two indices are defined, an outranking relation $S$ was defined by:

$$
S=A_{k} S A_{l} \quad \text { if and only if }\left\{\begin{array}{c}
C_{k l} \geq C_{l k} \\
d_{k l}<d_{l k} \\
>-d_{l k}
\end{array} \text { and also } C_{k l}\right.
$$

Equation 15 assures that $A_{k}$ outranks $A_{l}$ if the concordanceof $A_{k}$ exceedsconcordanceof $A_{l}$ and the discordance of $A_{k}$ is lower than discordance of $A_{l}$. 


\section{NUMERICAL EXAMPLE}

It is assumed that there are ten options $(A, B, C, \ldots, J)$ to be compared using six criteria [11]. These criterions areassumed on numerical scales, and much that high values are deemed preferable to low ones. Details of performance matrix are contained in Table I with its criterion weights.

To easy understanding the estimations, we will begin with the degree of deference of alternative $A$ with respect to all other alternatives as indicated in Table II.Max degrees of deference with respect to six criterions are indicated in Table III.The concordance contribution of alternative $A$ with respect to all other alternatives is illustrated in Table IV with the application of equations 4 and 6.

TABLE I. Performance matrix of alternatives with respect to criterion

\begin{tabular}{|c|c|c|c|c|c|c|c|}
\hline \multicolumn{2}{|c|}{ Criterion } & $C_{1}$ & $C_{2}$ & $C_{3}$ & $C_{4}$ & $C_{5}$ & $C_{6}$ \\
\hline \multicolumn{2}{|c|}{ CR.WE } & 0.25 & 0.1 & 0.15 & 0.25 & 0.05 & 0.2 \\
\hline \multirow{10}{*}{$\begin{array}{l}\stackrel{D}{ \pm} \\
\stackrel{\Xi}{ \pm} \\
\stackrel{\Xi}{ \pm}\end{array}$} & $\boldsymbol{A}$ & 6 & 300 & 27 & 18 & 570 & 12 \\
\hline & $\boldsymbol{B}$ & 2 & 450 & 21 & 19 & 400 & 23 \\
\hline & $C$ & 16 & 350 & 27 & 12 & 420 & 18 \\
\hline & $D$ & 10 & 500 & 20 & 12 & 450 & 20 \\
\hline & $E$ & 11 & 380 & 23 & 20 & 400 & 16 \\
\hline & $F$ & 5 & 250 & 31 & 10 & 430 & 18 \\
\hline & $G$ & 16 & 390 & 24 & 18 & 510 & 21 \\
\hline & $H$ & 17 & 400 & 22 & 26 & 380 & 23 \\
\hline & $I$ & 10 & 410 & 16 & 23 & 410 & 20 \\
\hline & $J$ & 5 & 250 & 18 & 21 & 400 & 22 \\
\hline
\end{tabular}

TABLE II. DEGREE OF DifFERENCE (D. D. $\left.A_{k} / A_{l}\right)$ OF ALTERNATIVES

\begin{tabular}{|c|c|c|c|c|c|c|}
\hline & $\boldsymbol{C}_{\mathbf{1}}$ & $\boldsymbol{C}_{\mathbf{2}}$ & $\boldsymbol{C}_{\mathbf{3}}$ & $\boldsymbol{C}_{\mathbf{4}}$ & $\boldsymbol{C}_{\mathbf{5}}$ & $\boldsymbol{C}_{\mathbf{6}}$ \\
\hline D.D.A/B & 4 & -150 & 6 & -1 & 170 & -11 \\
\hline D.D.A/C & -10 & -50 & 0 & 6 & 150 & -6 \\
\hline D.D.A/D & -4 & -200 & 7 & 6 & 120 & -8 \\
\hline D.D.A/E & -5 & -80 & 4 & -2 & 170 & -4 \\
\hline D.D.A/F & 1 & 50 & -4 & 8 & 140 & -6 \\
\hline D.D.A/G & -10 & -90 & 3 & 0 & 60 & -9 \\
\hline D.D.A/H & -11 & -100 & 5 & -8 & 190 & -11 \\
\hline D.D.A/I & -4 & -110 & 11 & -5 & 160 & -8 \\
\hline D.D.A/J & 1 & 50 & 9 & -3 & 170 & -10 \\
\hline
\end{tabular}

TABLE III. MAX DEGREe OF DifFERENCE $\left(M . D_{j} . A_{k}, A_{l}\right)$ UNDER EACH CRITERION

\begin{tabular}{|c|c|c|c|c|c|c|}
\cline { 2 - 7 } \multicolumn{1}{c|}{} & $\boldsymbol{C}_{\mathbf{1}}$ & $\boldsymbol{C}_{\mathbf{2}}$ & $\boldsymbol{C}_{\mathbf{3}}$ & $\boldsymbol{C}_{\mathbf{4}}$ & $\boldsymbol{C}_{\mathbf{5}}$ & $\boldsymbol{C}_{\mathbf{6}}$ \\
\hline $\boldsymbol{M} . \boldsymbol{D}_{\boldsymbol{j}}$ & 15 & 250 & 15 & 14 & 190 & 11 \\
\hline
\end{tabular}

Application of equations 8 and 10 are constructed in Table IV to extract the weighted concordance and discordance of alternative $A$ with respect to others. The weighted concordance and discordance of alternatives from $B$ to $j$ with respect to other alternatives are defined From Table VI up to Table XIV respectively. 
TABLE IV

The contribution of concordance and discordance of $A_{k}$ and $A_{l}$ under each criterion

\begin{tabular}{|c|c|c|c|c|c|c|}
\hline & $C_{1}$ & $C_{2}$ & $C_{3}$ & $C_{4}$ & $C_{5}$ & $C_{6}$ \\
\hline $\begin{array}{l}C_{j} \cdot A \\
/ B\end{array}$ & 0.27 & -0.6 & 0.4 & $\begin{array}{c}- \\
0.07\end{array}$ & 0.89 & -1 \\
\hline$C_{j} \cdot A / C$ & $\begin{array}{c}- \\
0.67\end{array}$ & -0.2 & 0 & 0.43 & 0.79 & 0.55 \\
\hline $\begin{array}{l}C_{j} \cdot A \\
/ D\end{array}$ & $0 . \overline{27}$ & -0.8 & 0.47 & 0.43 & 0.63 & $\begin{array}{c}- \\
0.73\end{array}$ \\
\hline$C_{j} \cdot A / E$ & $0 . \overline{33}$ & 0.32 & 0.27 & 0.14 & 0.89 & $0 . \overline{36}$ \\
\hline$C_{j} \cdot A / F$ & 0.07 & 0.2 & $0 . \overline{27}$ & 0.57 & 0.74 & $0 . \overline{55}$ \\
\hline$C_{j} \cdot A / G$ & $\begin{array}{c}- \\
0.67\end{array}$ & $0 . \overline{36}$ & 0.2 & 0 & 0.32 & $0 . \overline{82}$ \\
\hline $\begin{array}{l}C_{j} \cdot A \\
/ H\end{array}$ & 0.73 & -0.4 & 0.33 & 0.57 & 1 & -1 \\
\hline$C_{j} \cdot A / I$ & $0 . \overline{27}$ & $0 . \overline{44}$ & 0.73 & $0 . \overline{36}$ & 0.84 & $\begin{array}{c}- \\
0.73\end{array}$ \\
\hline$C_{j} \cdot A / J$ & 0.07 & 0.2 & 0.6 & $\overline{-}-\overline{21}$ & 0.89 & 0.91 \\
\hline
\end{tabular}

TABLE VI.

Degree of difference and concordance values of alternative $B$ with respect to other alternatives under each criterion

\begin{tabular}{|c|c|c|c|c|c|c|}
\hline & $C_{1}$ & $C_{2}$ & $C_{3}$ & $C_{4}$ & $C_{5}$ & $C_{6}$ \\
\hline $\begin{array}{l}\text { D.D.B } \\
/ A\end{array}$ & -4 & 150 & -6 & 1 & $\begin{array}{c}- \\
170 \\
\end{array}$ & 11 \\
\hline $\begin{array}{l}\text { D.D.B } \\
/ C\end{array}$ & -14 & 100 & -6 & 7 & -20 & 5 \\
\hline $\begin{array}{l}\text { D.D.B } \\
/ D\end{array}$ & -8 & -50 & 1 & 7 & -50 & 3 \\
\hline $\begin{array}{l}\text { D.D.B } \\
/ E\end{array}$ & -9 & 70 & -2 & -1 & 0 & 7 \\
\hline $\begin{array}{l}\text { D.D.B } \\
/ F\end{array}$ & -3 & 200 & -10 & 9 & -30 & 5 \\
\hline $\begin{array}{l}D . D . B \\
/ G\end{array}$ & -14 & 60 & -3 & 1 & $\begin{array}{c}- \\
110\end{array}$ & 2 \\
\hline $\begin{array}{l}\text { D.D.B } \\
/ H\end{array}$ & -15 & 50 & -1 & -7 & 20 & 0 \\
\hline D.D.B /I & -8 & 40 & 5 & -4 & -10 & 3 \\
\hline D.D.B /J & -3 & 200 & 3 & -2 & 0 & 1 \\
\hline
\end{tabular}

TABLE V

The weighted concordance and discordance values with respect to alternative $A$

\begin{tabular}{|c|c|c|c|c|c|c|}
\hline & $C_{1}$ & $C_{2}$ & $C_{3}$ & $C_{4}$ & $C_{5}$ & $C_{6}$ \\
\hline $\begin{array}{l}W_{j}\left(C_{j} A\right. \\
/ B)\end{array}$ & $\begin{array}{c}0.0 \\
7\end{array}$ & $\begin{array}{c}0.0 \\
6\end{array}$ & $\begin{array}{c}0.0 \\
6\end{array}$ & $\begin{array}{c}0.0 \\
2\end{array}$ & $\begin{array}{c}0.0 \\
5\end{array}$ & -0.2 \\
\hline $\begin{array}{l}W_{j}\left(C_{j} A\right. \\
/ C)\end{array}$ & $\begin{array}{c}- \\
0.1 \\
7\end{array}$ & $\begin{array}{c}- \\
0.0 \\
2\end{array}$ & 0 & $\begin{array}{c}0.1 \\
1\end{array}$ & $\begin{array}{c}0.0 \\
4\end{array}$ & $\begin{array}{c}- \\
0.1 \\
1\end{array}$ \\
\hline $\begin{array}{l}W_{j}\left(C_{j} A\right. \\
/ D)\end{array}$ & $\begin{array}{c}- \\
0.0 \\
7\end{array}$ & $\begin{array}{c}- \\
0.0 \\
8\end{array}$ & $\begin{array}{c}0.0 \\
7\end{array}$ & $\begin{array}{c}0.1 \\
1\end{array}$ & $\begin{array}{c}0.0 \\
3\end{array}$ & $\begin{array}{c}- \\
0.1 \\
5\end{array}$ \\
\hline $\begin{array}{l}W_{j}\left(C_{j} A\right. \\
/ E)\end{array}$ & $\begin{array}{c}- \\
0.0 \\
8\end{array}$ & $\begin{array}{c}- \\
0.0 \\
3\end{array}$ & $\begin{array}{c}0.0 \\
4\end{array}$ & $\begin{array}{c}- \\
0.0 \\
4\end{array}$ & $\begin{array}{c}0.0 \\
5\end{array}$ & $\begin{array}{c}- \\
0.0 \\
7\end{array}$ \\
\hline $\begin{array}{l}W_{j}\left(C_{j} A\right. \\
/ F)\end{array}$ & $\begin{array}{c}0.0 \\
2\end{array}$ & $\begin{array}{c}0.0 \\
2\end{array}$ & $\begin{array}{c}- \\
0.0 \\
4\end{array}$ & $\begin{array}{c}0.1 \\
4\end{array}$ & $\begin{array}{c}0.0 \\
4\end{array}$ & $\begin{array}{c}- \\
0.1 \\
1\end{array}$ \\
\hline $\begin{array}{l}W_{j}\left(C_{j} A\right. \\
/ G)\end{array}$ & $\begin{array}{c}0.1 \\
7 \\
\end{array}$ & $\begin{array}{c}0.0 \\
4 \\
\end{array}$ & $\begin{array}{c}0.0 \\
3\end{array}$ & 0 & $\begin{array}{c}0.0 \\
2\end{array}$ & $\begin{array}{c}0.1 \\
6 \\
\end{array}$ \\
\hline $\begin{array}{l}W_{j}\left(C_{j} A\right. \\
/ H)\end{array}$ & $\begin{array}{c}0.1 \\
8\end{array}$ & $\begin{array}{c}0.0 \\
4\end{array}$ & $\begin{array}{c}0.0 \\
5\end{array}$ & $\begin{array}{c}0.1 \\
4\end{array}$ & $\begin{array}{c}0.0 \\
5\end{array}$ & -0.2 \\
\hline$W_{j}\left(C_{j} A / I\right)$ & $\begin{array}{c}- \\
0.0 \\
7\end{array}$ & $\begin{array}{c}0.0 \\
4 \\
\end{array}$ & $\begin{array}{c}0.1 \\
1\end{array}$ & $\begin{array}{c}0.0 \\
9 \\
\end{array}$ & $\begin{array}{c}0.0 \\
4\end{array}$ & $\begin{array}{c}- \\
0.1 \\
5 \\
\end{array}$ \\
\hline$W_{j}\left(C_{j} A / J\right)$ & $\begin{array}{c}0.0 \\
2\end{array}$ & $\begin{array}{c}0.0 \\
2\end{array}$ & $\begin{array}{c}0.0 \\
9\end{array}$ & $\begin{array}{c}0.0 \\
5\end{array}$ & $\begin{array}{c}0.0 \\
5\end{array}$ & $\begin{array}{c}0.1 \\
8\end{array}$ \\
\hline
\end{tabular}

TABLE VII

Degree of difference and concordance values of alternative $C$ with respect other alternatives under each criterion

\begin{tabular}{|c|c|c|c|c|c|c|}
\hline & $C_{1}$ & $C_{2}$ & $C_{3}$ & $\boldsymbol{C}_{4}$ & $C_{5}$ & $C_{6}$ \\
\hline $\begin{array}{l}\text { D.D.C } \\
/ A\end{array}$ & 10 & 50 & 0 & -6 & $\begin{array}{c}- \\
150 \\
\end{array}$ & 6 \\
\hline $\begin{array}{l}\text { D.D.C } \\
/ B\end{array}$ & 14 & $\begin{array}{c}- \\
100 \\
\end{array}$ & 6 & -7 & 20 & -5 \\
\hline $\begin{array}{l}\text { D.D.C } \\
\text { /D }\end{array}$ & 6 & $\begin{array}{c}- \\
150\end{array}$ & 7 & 0 & -30 & -2 \\
\hline D.D. C /E & 5 & -30 & 4 & -8 & 20 & 2 \\
\hline D.D. C /F & 11 & 100 & -4 & 2 & -10 & 0 \\
\hline $\begin{array}{l}\text { D.D.C } \\
/ G\end{array}$ & 0 & -40 & 3 & -6 & -90 & -3 \\
\hline $\begin{array}{l}\text { D.D.C } \\
/ H\end{array}$ & -1 & -50 & 5 & -14 & 40 & -5 \\
\hline D.D. C /I & 6 & -60 & 11 & -11 & 10 & -2 \\
\hline D.D.C/J & 11 & 100 & 9 & -9 & 20 & -4 \\
\hline
\end{tabular}


TABLE VIII

Degree of difference and concordance values of alternative $D$ with respect toother alternatives under each criterion

\begin{tabular}{|c|c|c|c|c|c|c|}
\hline & $C_{1}$ & $C_{2}$ & $C_{3}$ & $C_{4}$ & $C_{5}$ & $C_{6}$ \\
\hline $\begin{array}{l}\text { D.D.D } \\
/ A\end{array}$ & 4 & 200 & -7 & -6 & $\begin{array}{c}- \\
120\end{array}$ & 8 \\
\hline $\begin{array}{l}\text { D.D.D } \\
/ \text { B }\end{array}$ & 8 & 50 & -1 & -7 & 50 & -3 \\
\hline $\begin{array}{l}\text { D.D.D } \\
/ C\end{array}$ & -6 & 150 & -7 & 0 & 30 & 2 \\
\hline $\begin{array}{l}\text { D.D.D } \\
\text { /E }\end{array}$ & -1 & 120 & -3 & -8 & 50 & 4 \\
\hline $\begin{array}{l}\text { D.D.D } \\
\text { /F }\end{array}$ & 5 & 250 & -11 & 2 & 20 & 2 \\
\hline $\begin{array}{l}\text { D.D.D } \\
/ G\end{array}$ & -6 & 110 & -4 & -6 & -60 & -1 \\
\hline $\begin{array}{l}\text { D.D.D } \\
/ H\end{array}$ & -7 & 100 & -2 & -14 & 70 & -3 \\
\hline D.D.D/I & 0 & 90 & 4 & -11 & 40 & 0 \\
\hline D.D.D/J & 5 & 250 & 2 & -9 & 50 & -2 \\
\hline
\end{tabular}

TABLE X

Degree of difference and concordance values of alternative $F$ with respect toother alternatives under each criterion

\begin{tabular}{|c|c|c|c|c|c|c|}
\hline & $C_{1}$ & $C_{2}$ & $C_{3}$ & $C_{4}$ & $C_{5}$ & $C_{6}$ \\
\hline $\begin{array}{l}\text { D.D.F } \\
\text { /A }\end{array}$ & -1 & -50 & 4 & -8 & $\begin{array}{c}- \\
140 \\
\end{array}$ & 6 \\
\hline $\begin{array}{l}\text { D.D.F } \\
/ B\end{array}$ & 3 & $\begin{array}{c}- \\
200\end{array}$ & 10 & -9 & 30 & -5 \\
\hline D.D.F $/ C$ & -11 & $\begin{array}{c}- \\
100\end{array}$ & 4 & -2 & 10 & 0 \\
\hline $\begin{array}{l}\text { D.D.F } \\
\text { /D }\end{array}$ & -5 & $\begin{array}{c}- \\
250\end{array}$ & 11 & -2 & -20 & -2 \\
\hline $\begin{array}{l}\text { D.D.F } \\
/ E\end{array}$ & -6 & $\begin{array}{c}- \\
130\end{array}$ & 8 & -10 & 30 & 2 \\
\hline $\begin{array}{l}\text { D.D.F } \\
/ G\end{array}$ & -11 & $\begin{array}{c}- \\
140\end{array}$ & 7 & -8 & -80 & -3 \\
\hline $\begin{array}{l}\text { D.D.F } \\
/ H\end{array}$ & -12 & $\begin{array}{c}- \\
150 \\
\end{array}$ & 9 & -16 & 50 & -5 \\
\hline D.D.F $/ I$ & -5 & $\begin{array}{c}- \\
160\end{array}$ & 15 & -13 & 20 & -2 \\
\hline D.D.F/J & 0 & 0 & 13 & -11 & 30 & -4 \\
\hline
\end{tabular}

TABLE IX

Degree of difference and concordance values of alternative $E$ with respect to other alternatives under each criterion

\begin{tabular}{|c|c|c|c|c|c|c|}
\hline & $C_{1}$ & $C_{2}$ & $C_{3}$ & $C_{4}$ & $C_{5}$ & $C_{6}$ \\
\hline $\begin{array}{l}\text { D.D.E } \\
/ A\end{array}$ & 5 & 80 & -4 & 2 & $\begin{array}{c}- \\
170 \\
\end{array}$ & 4 \\
\hline $\begin{array}{l}\text { D.D.E } \\
/ B\end{array}$ & 9 & -70 & 2 & 1 & 0 & -7 \\
\hline D. D. $E / C$ & -5 & 30 & -4 & 8 & -20 & -2 \\
\hline $\begin{array}{l}\text { D.D.E } \\
/ D\end{array}$ & 1 & $\begin{array}{c}- \\
120 \\
\end{array}$ & 3 & 8 & -50 & -4 \\
\hline $\begin{array}{l}\text { D.D.E } \\
/ F\end{array}$ & 6 & 130 & -8 & 10 & -30 & -2 \\
\hline $\begin{array}{l}\text { D.D.E } \\
/ G\end{array}$ & -5 & -10 & -1 & 2 & $\begin{array}{c}- \\
110 \\
\end{array}$ & -5 \\
\hline $\begin{array}{l}\text { D.D.E } \\
/ H\end{array}$ & -6 & -20 & 1 & -6 & 20 & -7 \\
\hline D.D.E/I & 1 & -30 & 7 & -3 & -10 & -4 \\
\hline D.D.E/J & 6 & 130 & 5 & -1 & 0 & -6 \\
\hline
\end{tabular}

TABLE XI

Degree of difference and concordance values of alternative $G$ with respect to other alternatives under each criterion

\begin{tabular}{|c|c|c|c|c|c|c|}
\hline & $C_{1}$ & $C_{2}$ & $C_{3}$ & $C_{4}$ & $C_{5}$ & $C_{6}$ \\
\hline $\begin{array}{l}\text { D.D.G } \\
/ A\end{array}$ & 10 & 90 & -3 & 0 & -60 & 9 \\
\hline $\begin{array}{l}\text { D.D.G } \\
/ B\end{array}$ & 14 & -60 & 3 & -1 & 110 & -2 \\
\hline $\begin{array}{l}\text { D.D.G } \\
/ C\end{array}$ & 0 & 40 & -3 & 6 & 90 & 3 \\
\hline $\begin{array}{l}\text { D.D.G } \\
/ D\end{array}$ & 6 & $\begin{array}{c}- \\
110 \\
\end{array}$ & 4 & 6 & 60 & 1 \\
\hline $\begin{array}{l}\text { D.D.G } \\
/ E\end{array}$ & 5 & 10 & 1 & -2 & 110 & 5 \\
\hline $\begin{array}{l}\text { D.D.G } \\
/ F\end{array}$ & 11 & 140 & -7 & 8 & 80 & 3 \\
\hline $\begin{array}{l}\text { D.D.G } \\
/ H\end{array}$ & -1 & -10 & 2 & -8 & 130 & -2 \\
\hline D.D. $G / I$ & 6 & -20 & 8 & -5 & 100 & 1 \\
\hline D.D.G/J & 11 & 140 & 6 & -3 & 110 & -1 \\
\hline
\end{tabular}


TABLE XII

Degree of difference and concordance values of alternative $H$ with respect toother alternatives under each criterion

\begin{tabular}{|c|c|c|c|c|c|c|}
\hline & $C_{1}$ & $C_{2}$ & $C_{3}$ & $C_{4}$ & $C_{5}$ & $C_{6}$ \\
\hline $\begin{array}{l}\text { D.D.H } \\
\text { /A }\end{array}$ & 11 & 100 & -5 & 8 & $\begin{array}{c}- \\
190\end{array}$ & 11 \\
\hline $\begin{array}{l}\text { D.D.H } \\
/ B\end{array}$ & 15 & -50 & 1 & 7 & -20 & 0 \\
\hline $\begin{array}{l}\text { D.D.H } \\
/ C\end{array}$ & 1 & 50 & -5 & 14 & -40 & 5 \\
\hline $\begin{array}{l}\text { D.D.H } \\
\text { /D }\end{array}$ & 7 & $\begin{array}{c}- \\
100 \\
\end{array}$ & 2 & 14 & -70 & 3 \\
\hline $\begin{array}{l}\text { D.D.H } \\
\text { /E }\end{array}$ & 6 & 20 & -1 & 6 & -20 & 7 \\
\hline $\begin{array}{l}\text { D.D.H } \\
/ F\end{array}$ & 12 & 150 & -9 & 16 & -50 & 5 \\
\hline $\begin{array}{l}\text { D.D.H } \\
/ G\end{array}$ & 1 & 10 & -2 & 8 & $\begin{array}{c}- \\
130 \\
\end{array}$ & 2 \\
\hline D.D. $H / I$ & 7 & -10 & 6 & 3 & -30 & 3 \\
\hline D.D. $H / J$ & 12 & 150 & 4 & 5 & -20 & 1 \\
\hline
\end{tabular}

TABLE XIV

Degree of difference and concordance values of alternative $J$ with respect toother alternatives under each criterion
TABLE XIII

Degree of difference and concordance values of alternative $I$ with respect to other alternatives under each criterion

\begin{tabular}{|c|c|c|c|c|c|c|}
\hline & $C_{1}$ & $C_{2}$ & $C_{3}$ & $C_{4}$ & $C_{5}$ & $C_{6}$ \\
\hline L & 4 & 110 & -11 & 5 & $\begin{array}{c}- \\
160\end{array}$ & 8 \\
\hline D.D.I /B & 8 & -40 & -5 & 4 & 10 & -3 \\
\hline D.D.I/C & -6 & 60 & -11 & 11 & -10 & 2 \\
\hline D. D. I/D & 0 & -90 & -4 & 11 & -40 & 0 \\
\hline D. D. I /E & -1 & 30 & -7 & 3 & 10 & 4 \\
\hline D. D. I /F & 5 & 160 & -15 & 13 & -20 & 2 \\
\hline D.D. I / G & -6 & 20 & -8 & 5 & $\begin{array}{c}- \\
100\end{array}$ & -1 \\
\hline D.D.I/H & -7 & 10 & -6 & -3 & 30 & -3 \\
\hline D.D.I/J & 5 & 160 & -2 & 2 & 10 & -2 \\
\hline
\end{tabular}

\begin{tabular}{|l|c|c|c|c|c|c|}
\cline { 2 - 7 } & $\boldsymbol{C}_{\mathbf{1}}$ & $\boldsymbol{C}_{\mathbf{2}}$ & $\boldsymbol{C}_{3}$ & $\boldsymbol{C}_{\mathbf{4}}$ & $\boldsymbol{C}_{\mathbf{5}}$ & $\boldsymbol{C}_{\mathbf{6}}$ \\
\hline D.D.J/A & -1 & -50 & -9 & 3 & - & 10 \\
\hline D.D.J/B & 3 & - & -3 & 2 & 0 & -1 \\
\hline D.D.J/C & -11 & - & -9 & 9 & -20 & 4 \\
\hline D.D.J/D & -5 & - & -2 & 9 & -50 & 2 \\
\hline D.D.J/E & -6 & - & -5 & 1 & 0 & 6 \\
\hline D.D.J/F & 0 & 0 & -13 & 11 & -30 & 4 \\
\hline D.D.J/G & -11 & - & -6 & 3 & - & 1 \\
\hline D.D.J/H & -12 & - & -4 & -5 & 20 & -1 \\
\hline D.D.J/I & -5 & - & 2 & -2 & -10 & 2 \\
\hline
\end{tabular}

TABLE XV. CONCORDANCE MATRIX, $\boldsymbol{C}=\mathbf{0 . 1 9 6 2 4}$

\begin{tabular}{|c|c|c|c|c|c|c|c|c|c|c|c|}
\hline & $\boldsymbol{A}$ & $\boldsymbol{B}$ & $\boldsymbol{C}$ & $\boldsymbol{D}$ & $\boldsymbol{E}$ & $\boldsymbol{F}$ & $\boldsymbol{G}$ & $\boldsymbol{H}$ & $\boldsymbol{I}$ & $\boldsymbol{J}$ & $\boldsymbol{P} . \boldsymbol{A}_{\boldsymbol{k}}$ \\
\hline $\boldsymbol{A}$ & 0 & 0.17 & 0.15 & 0.21 & 0.08 & 0.22 & 0.05 & 0.10 & 0.15 & 0.17 & 1.30 \\
\hline $\boldsymbol{B}$ & 0.28 & 0 & 0.26 & 0.19 & 0.16 & 0.33 & 0.08 & 0.03 & 0.07 & 0.13 & 1.51 \\
\hline $\boldsymbol{C}$ & 0.30 & 0.30 & 0 & 0.17 & 0.16 & 0.26 & 0.03 & 0.06 & 0.21 & 0.32 & 1.81 \\
\hline $\boldsymbol{D}$ & 0.29 & 0.17 & 0.10 & 0 & 0.13 & 0.26 & 0.04 & 0.06 & 0.09 & 0.22 & 1.36 \\
\hline $\boldsymbol{E}$ & 0.22 & 0.19 & 0.15 & 0.19 & 0 & 0.33 & 0.04 & 0.02 & 0.09 & 0.20 & 1.43 \\
\hline $\boldsymbol{F}$ & 0.15 & 0.16 & 0.04 & 0.11 & 0.12 & 0 & 0.07 & 0.10 & 0.16 & 0.14 & 1.05 \\
\hline $\boldsymbol{G}$ & 0.37 & 0.29 & 0.20 & 0.28 & 0.22 & 0.46 & 0 & 0.05 & 0.22 & 0.33 & 2.42 \\
\hline $\boldsymbol{H}$ & 0.57 & 0.39 & 0.38 & 0.44 & 0.34 & 0.64 & 0.20 & 0 & 0.28 & 0.41 & 3.64 \\
\hline $\boldsymbol{I}$ & 0.35 & 0.21 & 0.26 & 0.20 & 0.14 & 0.42 & 0.10 & 0.01 & 0 & 0.19 & 1.86 \\
\hline $\boldsymbol{J}$ & 0.24 & 0.09 & 0.23 & 0.20 & 0.13 & 0.27 & 0.07 & 0.01 & 0.06 & 0 & 1.28 \\
\hline
\end{tabular}


TABLE XVI. DISCORDANCE MATRIX, $\boldsymbol{d}=\mathbf{- 0 . 1 9 6 8}$

\begin{tabular}{|c|c|c|c|c|c|c|c|c|c|c|c|}
\hline & $\boldsymbol{A}$ & $\boldsymbol{B}$ & $\boldsymbol{C}$ & $\boldsymbol{D}$ & $\boldsymbol{E}$ & $\boldsymbol{F}$ & $\boldsymbol{G}$ & $\boldsymbol{H}$ & $\boldsymbol{I}$ & $\boldsymbol{J}$ & $\boldsymbol{D} . \boldsymbol{A}_{\boldsymbol{k}}$ \\
\hline $\boldsymbol{A}$ & 0 & -0.28 & -0.30 & -0.29 & -0.22 & -0.15 & -0.37 & -0.57 & -0.35 & -0.24 & -2.75 \\
\hline $\boldsymbol{B}$ & -0.17 & 0 & -0.30 & -0.17 & -0.19 & -0.16 & -0.29 & -0.39 & -0.21 & -0.09 & -1.95 \\
\hline $\boldsymbol{C}$ & -0.15 & -0.26 & 0 & -0.10 & -0.15 & -0.04 & -0.20 & -0.38 & -0.26 & -0.23 & -1.77 \\
\hline $\boldsymbol{D}$ & -0.21 & -0.19 & -0.17 & 0 & -0.19 & -0.11 & -0.28 & -0.44 & -0.20 & -0.20 & -1.98 \\
\hline $\boldsymbol{E}$ & -0.08 & -0.16 & -0.16 & -0.13 & 0 & -0.12 & -0.22 & -0.34 & -0.14 & -0.13 & -1.49 \\
\hline $\boldsymbol{F}$ & -0.22 & -0.33 & -0.26 & -0.26 & -0.33 & 0 & -0.46 & -0.64 & -0.42 & -0.27 & -3.18 \\
\hline $\boldsymbol{G}$ & -0.05 & -0.08 & -0.03 & -0.04 & -0.04 & -0.07 & 0 & -0.20 & -0.10 & -0.07 & -0.67 \\
\hline $\boldsymbol{H}$ & -0.10 & -0.03 & -0.06 & -0.06 & -0.02 & -0.10 & -0.05 & 0 & -0.01 & -0.01 & -0.43 \\
\hline $\boldsymbol{I}$ & -0.15 & -0.12 & -0.21 & -0.09 & -0.09 & -0.16 & -0.22 & -0.28 & 0 & -0.06 & -1.38 \\
\hline $\boldsymbol{J}$ & -0.17 & -0.13 & -0.32 & -0.22 & -0.20 & -0.14 & -0.33 & -0.41 & -0.19 & 0 & -2.10 \\
\hline
\end{tabular}

After construction of the concordance and discordance matrices from the previous tables, the requirements are the priority of alternatives, outranking relations between alternatives. From Tables XV and XVI, the priority vectors of concordance and discordance are estimated $\left(P . A_{k}\right.$ and $\left.D . A_{k}\right)$ and then the overall score of alternatives can be constructed from $R . V$ (equation 15) as indicated in Table XVII. In Table XVII, the priority of concordance and discordance was summed to be the $R . V$ vector that is the overall score of priority of all alternatives.

Thus, it is now necessary to start to identify patterns of dominance among the options, using the conditions in equation 19. Here, this yields the following initial dominance pattern for each alternative and the number of dominated alternatives with it and identification as in Table XVIII.

The new technique has one advantage than other methods where it constructs a complete relation between all alternatives and there is not a relation that contradict with them. Each relation has number of dominations varying than others, which is the road of ranking and outranking. In begins with the lowest domination, then $F$ is the lowest alternative, the next is the relation that has one dominated. This is found in relation one, which dominates $F$, so $A$ is the previous of $F$. thus alternative $F$ becomes number ten and $A$ has number nine in ranking. The next relation is the relation that has two dominated which is relation number nine which $J$ dominates $A$ and $F$. So, alternative $J$ becomes number eight in ranking. This procedure gives that same ranking from $R . V$ vector and extract that the alternative, which has a high score, outranks all alternatives lower it.

When we subtract the number of alternatives from the dominated alternatives from each alternative, this extracts the ranking of alternative. As example in relation 10, $A$ and $F$ are dominated from $J$ so, alternative $J$ has ranking equal $10-2=8$, where 10 is the number of alternatives. Also, in relation 8 the alternative $H$ has a ranking number one $(10-9=1)$. Finally, ranking of alternatives as indicated in Table XVII arranged as follows HGICEBDJAF. This analysis is true for alternatives more than three.

TABLE XVII. RANKING OF ALTERNATIVES HGICEBDJAF

\begin{tabular}{|c|c|c|c|c|c|c|}
\hline & $\boldsymbol{P}$ & $\boldsymbol{I D} / \boldsymbol{P}$ & $\boldsymbol{T} . \boldsymbol{D}$ & $\boldsymbol{I D} / \boldsymbol{T} . \boldsymbol{D}$ & $\boldsymbol{R} . \boldsymbol{V}$ & $\boldsymbol{I D} / \boldsymbol{R} . \boldsymbol{V}$ \\
\hline $\boldsymbol{A}$ & 1.30 & 9.00 & -2.75 & 9.00 & -1.45 & 9.00 \\
\hline $\boldsymbol{B}$ & 1.51 & 5.00 & -1.95 & 6.00 & -0.44 & 6.00 \\
\hline $\boldsymbol{C}$ & 1.81 & 4.00 & -1.77 & 5.00 & 0.04 & 4.00 \\
\hline $\boldsymbol{D}$ & 1.36 & 7.00 & -1.98 & 7.00 & -0.62 & 7.00 \\
\hline $\boldsymbol{E}$ & 1.43 & 6.00 & -1.49 & 4.00 & -0.06 & 5.00 \\
\hline $\boldsymbol{F}$ & 1.05 & 10.00 & -3.18 & 10.00 & -2.13 & 10.00 \\
\hline $\boldsymbol{G}$ & 2.42 & 2.00 & -0.67 & 2.00 & 1.75 & 2.00 \\
\hline $\boldsymbol{H}$ & 3.64 & 1.00 & -0.43 & 1.00 & 3.21 & 1.00 \\
\hline $\boldsymbol{I}$ & 1.86 & 3.00 & -1.38 & 3.00 & 0.48 & 3.00 \\
\hline $\boldsymbol{J}$ & 1.28 & 8.00 & -2.10 & 8.00 & -0.81 & 8.00 \\
\hline SUM & 17.66 & SUM & -17.71 & & & \\
\cline { 1 - 2 }
\end{tabular}


TABLE XVIII. INITIAL DOMINANCE PATTERN FOR EACH ALTERNATIVE

\begin{tabular}{|c|c|c|c|}
\hline No. & Alternative & $\begin{array}{c}\text { Dominated } \\
\text { alternatives }\end{array}$ & $\begin{array}{c}\text { Number of dominated } \\
\text { alternatives }\end{array}$ \\
\hline $\mathbf{1}$ & $A$ & $F$ & $(1)$ \\
\hline $\mathbf{2}$ & $B$ & $A, D, F, J$ & $(4)$ \\
\hline $\mathbf{3}$ & $C$ & $A, B, D, E, F, J$ & $(6)$ \\
\hline $\mathbf{4}$ & $D$ & $A, F, J$ & $(3)$ \\
\hline $\mathbf{5}$ & $E$ & $A, B, D, F, J$ & $(5)$ \\
\hline $\mathbf{6}$ & $F$ & $N o n$ & $(0)$ \\
\hline $\mathbf{7}$ & $G$ & $A, B, C, D, E, F, I, J$ & $(8)$ \\
\hline $\mathbf{8}$ & $H$ & $A, B, C, D, E, F, G, I, J$ & $(9)$ \\
\hline $\mathbf{9}$ & $I$ & $A, B, C, D, E, F, J$ & $(7)$ \\
\hline $\mathbf{1 0}$ & $J$ & $A, F$ & $(2)$ \\
\hline
\end{tabular}

\section{DISCUSSION}

ELECTRE methods yield a whole system of binary outranking relations between the alternatives. Because the system is not necessarily complete, the ELECTRE method is sometimes unable to identify the preferred alternatives. It only produces a core of leading alternatives [16]. ELECTRE method has a clear view of alternatives by eliminating less favourable ones, especially convenient while encountering few criteria with large number of alternatives in a decision-making problem [18]. Through a series of consecutive assessments of the outranking relations of alternatives, ELECTRE elicits the so-called concordance index, defined as the amount of evidence to support the conclusion that $A_{k}$ outranks or dominates $A_{l}$, as well as, the discordance, the counter-part of concordance index.

The basic concept of the ELECTRE method deal with outranking relations by using pairwise comparisons among alternatives under each one of the criteria separately to extract the concordance and discordance sets. The suggested new technique, Keen Analysis Surge of Advantage States [KASAS] shows that the concordance sets are based on unfairness condition that make redundant scores for alternative which also gives an imprecise advantage for one or more alternative than others. These advantages are indicated in the equality of the classification of concordance and discordance sets, where $a_{k j} \geq a_{l j}$, then $A_{k}$ primarily is preferred than $A_{l}$ and the criterion $j$ becomes in the concordance set. The condition makes redundant scores for alternatives $A_{k}$ and $A_{l}$ during equality of performance and score of concordance is added in two evaluations $A_{k} / A_{l}$ and $A_{l} / A_{k}$ without distinguishes between two alternatives. Therefore, the new technique suggests that deleting the equality from concordance set condition. As a result, from this suggestion is indicated in Table II when comparing $A / C$ with respect to $C_{3}$ and $A / G$ with respect to $C_{4}$. From this analysis, the concordance set is restricted with the elements that have advantages than others.

The second step in ELECTRE technique is the construction of concordance and discordance indices. The concordance index equals the sum of weights with the members of the concordance set anyhow the type of outranking relation that decided to the nature of concordance relation (power and strongest). The concordance or discordance assures with the validation of relation of outranking and ranging with respect to outranking relation regardless recognizing the radical degree of performance of each alternative with respect to others concerning each criterion. Therefore, the new technique suggests that known the degree of difference between alternatives under each criterion. If these degrees are known for each alternative with respect to others, so, it is normalized with respect to maximum difference about its criteria. Normalization operation gives the contribution of relations between one alternative to others for all concordance and discordance indices as indicated in each column in Table IV. the concordance and discordance degrees not only depend on the normalized degree of difference but also depends on the criterion weights that enhance and constitute the effect of difference between alternatives. The weighted concordance $C_{k l}$ and discordance $d_{l k}$ members give a monitoring of the outranking relations between one alternative to others. From the nature of estimations inside the new technique it is shown that, measuring units of concordance and discordance are the same units and there is not a contradiction of units which also candidates this technique to be a dimensionless analysis with conflicting criteria. From concordance and discordance matrices, it is able to validate the preference of alternatives and get the actual outranking and ranking relations. 


\section{VI.CONCLUSION}

From the weakness in the ELECTRE techniques and its shortages that have been indicated in most researches, this paper introduced a new dimensionless technique with conflicting criteria. This technique is a Keen Analysis Surge of Advantage States [KASAS] which able to deals with the decision problems under the presence of number of decision criteria. This technique has a power to deal with the conflicting criteria and incommensurable units. The new technique used a new adjustment of nature of concordance and discordance indicies. It is indicated the contribution of advatage of one alternative in related to ather alternatives contributions in the direction of dominance by the degree of difference. This technique is called dimensionless analysis because its structure eliminates any units of measure, which uses relative ratios insteadof actual ones. Thus, it can be used in single or multi-dimensional decision making problems. This technique ha a capability to identify the outranking relations between any two alternatives without shortage, delete the old understanding of imposibility of getting an outranking relation. Priority score is the advantage of this method offered through computation of composite priorities of the alternatives by linearly adding the weighted cocordance and dicordance indecies values. The priority vector of alternatives in this technique is the effective tool to make a correct and complete ranking of alternatives.

\section{REFERENCES}

[1] Brugha, C. M., "Structuring and weighting criteria in multi criteria decision making (MCDM)," In Trends in multicriteria decision making, 229-242, Springer, Berlin, Heidelberg, 1998.

[2] Buchanan, J. T., Sheppard, P. J., and Vanderpooten, D., "Project ranking using ELECTRE III," Department of Management Systems, University of Waikato, 1999.

[3] Buchanan, J. T., Henig, E. J., and Henig, M. I., "Objectivity and subjectivity in the decision making process," Annals of Operations Research, 80, 333-345, 1998.

[4] Zamani-Sabzi, H., King, J. P., Gard, C. C., and Abudu, S., "Statistical and analytical comparison of multi-criteria decision-making techniques under fuzzy environment," Operations Research Perspectives, 3, 92-117, 2016.

[5] Henig, M. I., and Buchanan, J. T., "Solving MCDM problems: Process concepts," Journal of Multi Criteria Decision Analysis, 5(1), $3-21,1996$

[6] Hokkanen, J., and Salminen, P., "ELECTRE III and IV decision aids in an environmental problem," Journal of Multi Criteria Decision Analysis, 6(4), 215-226, 1997.

[7] Rogers, M., and Bruen, M., "Choosing realistic values of indifference, preference and veto thresholds for use with environmental criteria within ELECTRE,” European Journal of Operational Research, 107(3), 542-551, 1998.

[8] Rogers, M., and Bruen, M., "A new system for weighting environmental criteria for use within ELECTRE III," European Journal of Operational Research, 107(3), 552-563, 1998.

[9] Roy, B., "Classement et choix en présence de points de vue multiples," Revue française d'informatique et de recherche opérationnelle, 2(8), 57-75, 1968.

[10] Roy, B., "The outranking approach and the foundations of ELECTRE methods," In Readings in multiple criteria decision aid, 155-183, Springer, Berlin, Heidelberg, 1990.

[11] Roy, B.,"The Outranking Approach and the Foundations of the ELECTRE Methods," Theory and Decision, 31, 49-73, 1991.

[12] Roy, B.,"Decision-aiding today: What should we expect?," Multicriteria Decision Making, Springer, Boston, MA, 1-35, 1991.

[13] Roy, B., and Mousseau, V., "A theoretical framework for analysing the notion of relative importance of criteria," Journal of Multi Criteria Decision Analysis, 5(2), 145-159, 1996.

[14] Mary, S. S. A., and Suganya, G., "Multi-criteria decision making using ELECTRE," Circuits and Systems, 7(06), 1008, 2016.

[15] Simpson, L., "Do decision makers know what they prefer?: MAVT and ELECTRE II," Journal of the Operational Research Society, 47(7), 919-929, 1996.

[16] Triantaphyllou, E., Shu, B., Sanchez, S. N., and Ray, T., "Multi-criteria decision making: an operations research approach," Encyclopedia of electrical and electronics engineering, 15(1998), 175-186, 1998.

[17] Vanderpooten, D., "The construction of prescriptions in outranking methods," In Readings in multiple criteria decision aid, 184-215, Springer, Berlin, Heidelberg, 1990.

[18] Lootsma, F. A., "The French and the American school in multi-criteria decision analysis," RAIRO-Operations Research-Recherche Opérationnelle, 24(3), 263-285, 1990.

\section{AUTHOR PROFILE}

Ahmed M. El-kassas is an associate professor at Tanta University in Egypt. He teaches the operations research and industrial engineering courses in the Department of Production Engineering and Mechanical Design at Faculty of Engineering - Tanta University. He is author and co-author of various international publications. 